\title{
Implementation of Decision Support System on m/f Wolin.
}

\author{
Piotr Wołejsza \\ Maritime University of Szczecin \\ Wały Chrobrego Str. 1-2, 70-500 \\ Szczecin, Poland \\ Email: piotr@am.szczecin.pl
}

\begin{abstract}
The known navigational systems in use and methods of navigational decision support perform information functions and as such are helpful in the process of safe conduct of a vessel. However, none of these known systems provides a navigator with ready solutions of collision situations taking account of all the vessels in the proximity of own ship, where the Collision Regulations apply. This paper presents verification results of NAVDEC - new Navigational Decision Supporting System created by research team from Szczecin Maritime University both for ocean going ships and pleasure crafts. Successful verification was carried out in real condition on board Motor Ferry Wolin (m/f Wolin), which belongs to shipowner UnityLine.
\end{abstract}

\section{INTRODUCTION}

$\mathrm{T}$ HE competitive position of maritime transport compared to the other transport modes leads to a continuous increase in the carriage of goods by sea, which entails higher traffic intensity, vessel tonnages and speeds. This, in turn, adversely affects the safety of people, ships, cargo and marine environment. To enhance navigational safety, efficiency and competitiveness of transport services in maritime trade, both ships' and land-based vessel traffic centres' equipment and systems are constantly being upgraded. Such facilities perform mainly information functions and in this respect they support the process of safe ship conduct. However, the amount of information available on the ship has been on the rise while the technical systems have become more complex. For these reasons both information management and the resultant decision making are difficult, e.g. emergency situations may go beyond decision-maker's abilities.

A review of maritime court decisions indicates that human errors are one of the major causes of marine accidents. Elimination or reduction of human errors, which would provide for possibly high safety level, can be achieved only by equipping ships with tools that, apart from information functions, will work out solutions to collision situations accompanied by adequate comments. None of the systems known to date is capable of performing such functions. Therefore, decision support is rather restricted, and, consequently, collisions sometimes are not avoided. A higher level of navigational safety gained through the introduction of the system performing the new functionalities will reduce the risk of marine accidents. This will bring the following advantages:

- social benefits due to lower rate of personnel injuries and loss of life on sea-going ships,

- material benefits due to lower loss of cargo, less damage to ships or sinkings,

- marine environment protection and prevention of ecological disasters that occur as a consequence of collision of ships carrying dangerous goods.

The navigational decision support system NAVDEC is the first navigational tool worldwide that performs information functions as well as those typical of decision support systems. Its innovative functionalities, significantly extending the performance of devices generally carried by ships, have now a status of patent applications filed at home and internationally.

\section{TEST ENVIRONMENT}

$\mathrm{M} / \mathrm{F}$ Wolin is a train, car and passenger ferry owned by the Unity Line. She was built in 1986. It has been in Unity Line colours since 2007. It is the longest ferry on Świnoujście - Trelleborg route.

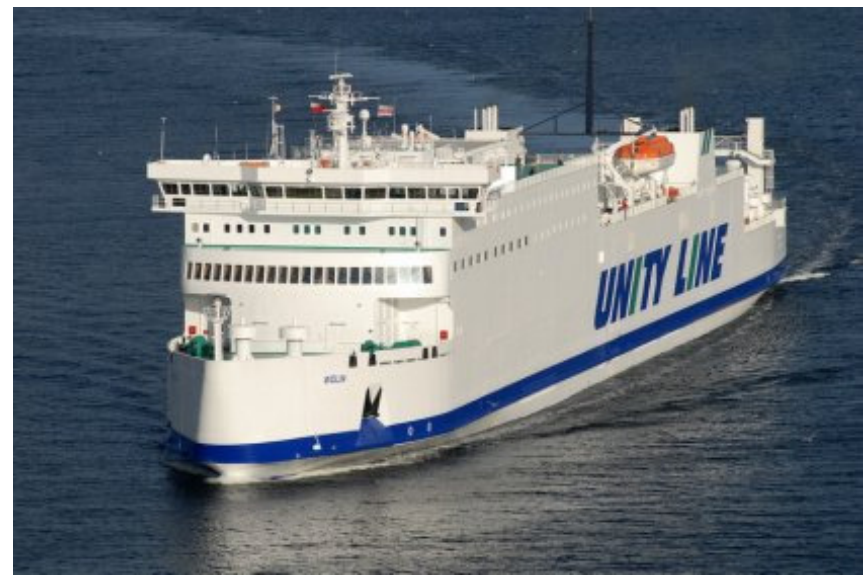

Fig. $1 \mathrm{M} / \mathrm{F}$ Wolin [1]

The author wants to thank for the financial support to Ministry of Science and Higher Education. 


$\begin{array}{ll}\text { Call sign } & \text { C6WN4 } \\ \text { Length } & 188,9 \mathrm{~m} \\ \text { Breadth } & 23,1 \mathrm{~m} \\ \text { Draught } & 5,9 \mathrm{~m} \\ \text { Maximum speed } & 18 \text { knots } \\ \text { Crew } & 37 \\ \text { Passengers capacity } & 370 \\ \text { Cabins } & 70 \\ \text { Beds } & 240\end{array}$

First test installation took place 14-15 of September 2014. During the journey to/from Trelleborg few deficiencies were observed. Corrections in the source code were done and from $16^{\text {th }}$ of December 2014 NAVDEC is in continuous use on $\mathrm{m} / \mathrm{f}$ Wolin.

NAVDEC is installed on the portable computer Hewlett Packard ProBook 6555b (processor ADM Athlon II P340 Dual Core $2.2 \mathrm{GHz}$, hard drive $256 \mathrm{~GB}, 2$ GB RAM) with 32 bit Windows 7 together with C-MAP Professional + chart license. Computer is connected to ship's system via two cables:

1. AIS (Automatic Identification System) Pilot Plug to RS 232,

2. ARPA (Automatic Radar Plotting Aids) to RS 232 cargo and/or environmental damage), is more than one million USD, while the average sum of hull and machinery damages paid by insurance companies is of two billion USD yearly [2]. The European Quality Shipping Information System database (www.equasis.org) quantifies merchant vessels at over 77 thousand worldwide, of which around $2.5 \%$ come into collision every year, while the Helsinki Commission (HELCOM), which monitors the Baltic Sea, cites collisions as the main type of accidents, accounting for $38 \%$ of the total in that area [4].

The Swedish Club report concludes that the majority of these collisions could have been prevented by following safety protocols, but the fact is that sea-going vessels lack dedicated support systems to address potential collision situations. This is the purpose of NAVDEC, a navigational decision system designed to support vessel officers in efficient collision avoidance following COLREGs rules. The need for such systems has been confirmed by the International Maritime Organization forum developing enavigation strategies [5] and by key stakeholders involved in the development of the NAVDEC prototype currently pilot testing in real work environment (TRL 7).

NAVDEC uses the navigation system data to provide fast and accurate options to the OOW, including the most important variables to be considered:

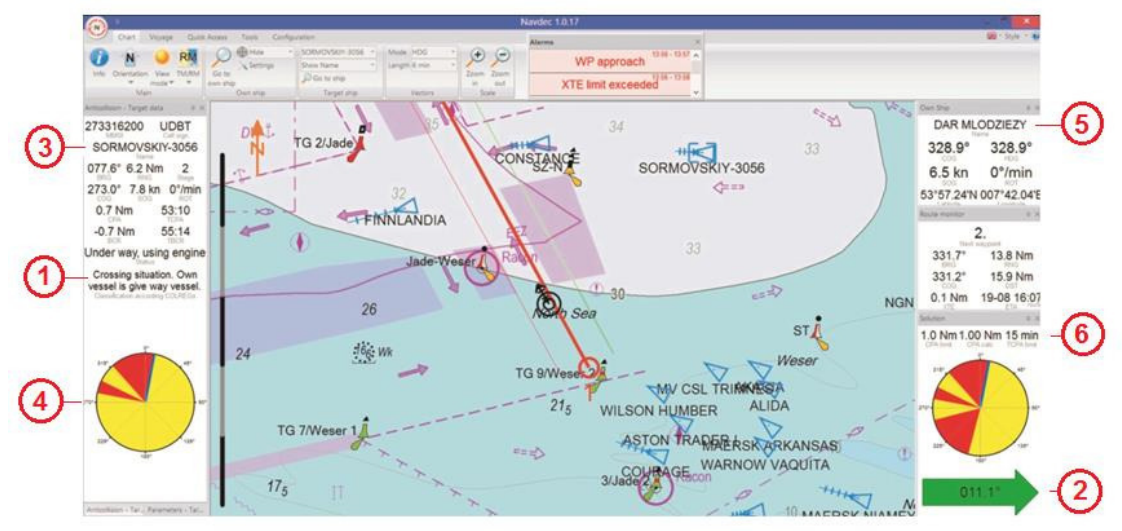

Fig. 2 NAVDEC in action: real screenshot from the NAVDEC pilot test at sea on the Dar Mlodziezy, showing main components.

\section{NAVDEC}

Marine accidents represent a major risk for personnel, cargo, vessels and the environment. According to marine mutual insurer The Swedish Club, one of the main causes of vessel collisions is that the Officer Of the Watch (OOW) did not follow International Regulations for Preventing Collisions at Sea (COLREGs) or their company's Safety Management System [2]. Marine insurance statistics have shown that human error is a major contributing factor in about $60 \%$ of shipping accidents, with other research suggesting that this figure significantly increases in the case of collisions and groundings [3].

The average cost of ship collision, taking account hull repair cost alone (excluding the costs of medical care, lost
1. Classification of encounter situation according to COLREGs ("crossing situation", "head on situation" or "overtaking") and which vessel is "stand on" (has right of way) and "give way" (must let the other pass)

2. Optimal course to avoid collision

3. Target data

4. Solutions for selected target

5. Own vessel data: destination, distance to go, ETA, etc.

6. Solutions how to pass all targets at predetermined distance from our vessel.

When the own vessel is "give way" in relation to at least one target, NAVDEC displays a compass rosette with solutions (6), with red sectors indicating collision risk and 
yellow sectors indicating safe courses in which the vessel will pass other targets on predetermined CPA or larger distance. Below the rose is the optimal course requiring smallest deviation from current course: a green arrow indicates starboard turn, red arrow for port turn.

Navigational systems installed on vessels are information systems which acquire, process, gather and display information to the ship's navigator, who makes decisions after analysing the data and assessing the situation. Rough weather conditions, heavy traffic, stress or fatigue may provoke errors in situation assessment and lead to a wrong decision. The implementation of decision support will help reduce the number of such errors and enhance the safety and efficiency of maritime transport, while also leveraging a necessary technological component of future unmanned enavigation vessels. Moreover, the system optimizes the anticollision manoeuvres to reduce fuel consumption, which is the main component of the cost of transport. [6]

In a 2014 report by the NCSR IMO Sub-Committee in London, the e-navigation group of the International Maritime Organization stated "[...] It is important to recognize that further e-navigation development will be a continuous process following user needs for additional functionalities of existing and possible future systems (e.g. implementation of onboard and/or ashore navigational decision support systems). "'[5]

One of the ways to reduce the number and consequences of marine accidents is the application of shipborne navigational systems that, apart from information, perform decision support functions: automatically generate suggested solutions to collision situations, leaving the choice to the navigator. The lack of such systems on the market creates opportunities for companies dealing with their production and implementation.

NAVDEC is a real time system handled by the navigator that complements the navigational equipment of the ship. The system observes its ship and the environment and records information on the present navigational situation. On this basis the system identifies and assesses the navigational situation (processing) and works out solutions (decisions) assuring safe navigation.

For the system to function correctly it must cooperate with standard equipment and systems installed on board (often used on leisure craft as well) such as: log, gyrocompass, ARPA, GNSS (Global Navigational Satellite System), AIS (Automatic Identification System), ENC (Electronic Navigational Chart) and sources of current navigational data. NAVDEC performs information functions - on one screen it presents bathymetric data from an electronic chart, an image of surface situation from a tracking radar, positional information from the AIS and GNSS receivers. Finally, it determines and presents to the navigator movement parameters of targets in vicinity. [7]

The navigational decision support system NAVDEC is the first navigational tool worldwide that performs information functions as well as those typical of decision support systems. NAVDEC goes beyond the current functions of information systems such as ECDIS (Electronic Chart Display and Information System) and ARPA (Automatic Radar Plotting Aids) by offering the following advanced functions:

- fusion and integration of navigational data received from shipboard devices

- analysis and assessment of situation taking into consideration the Collision Regulations in force

- automatic determination of solutions to collision situations by using dedicated computational algorithms

- explanation of the present navigational situation making use of a navigational knowledge base (collision regulations, principles of good sea practice, criteria of navigational situation analysis and assessment actually used by expert navigators)

- justification of the recommended manoeuvre. [8]

Compared to the ARPA system, presently used on ships for calculating ship encounter parameters and working out an anti-collision manoeuvre, the developed NAVDEC system has the following advantages:

- account for the Collision Regulations for good and restricted visibility,

- generates a manoeuvre in relation to other ships, also those located in the radar blind sector,

- operator is immediately notified of a manoeuvre commenced by another ship (target) thanks to information about rate of turn of the target, and the system needs a few seconds to calculate encounter parameters, while ARPA, according to IMO's test situations, needs three minutes for this action,

- more accurately calculates encounter parameters, as it takes into account ship's dimensions, and uses GPS for position determination by special algorithms executing data fusion,

- takes into account the sizes of ships while planning an anti-collision manoeuvre,

- calculates such new courses and speeds of own ship that passing other targets is possible maintaining the predetermined closest point of approach (CPA). [9]

\section{DECISION SUPPORT SYSTEM}

Developed at the Maritime University of Szczecin NAVDEC system is a navigation tool that performs alongside providing information typical tasks for decision support systems. NAVDEC is an important complement to navigational equipment of the ship. Is a real-time system operated by the navigator. Its proper functioning requires interaction with devices and systems on the ship. The standard configuration of the ship include: log, gyrocompass, radar, echo sounder, ARPA, GNSS (Global Navigational Satellite System), such as GPS (Global Positioning System) 
or DGPS (Differential Global Positioning System). In addition, AIS, ECDIS, GNSS [10]. In the version being developed following sources of information are in use: log, gyrocompass, radar / ARPA, GPS and DGPS, AIS and ENC (Fig.3).

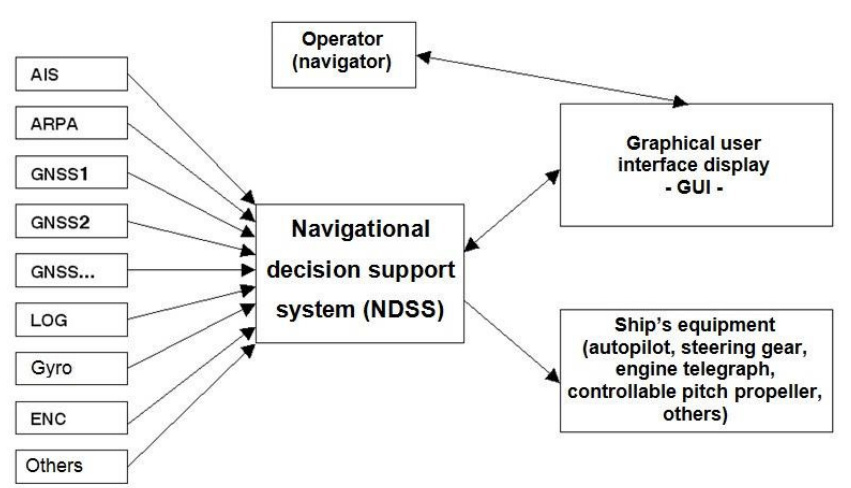

Fig. 3. Data sources for decision supporting system [9]

The system's structure (Fig.4) has been prepared in such a way so as to make possible the simultaneous performance of tasks bound with supporting decision-making processes in the conduct of a ship.

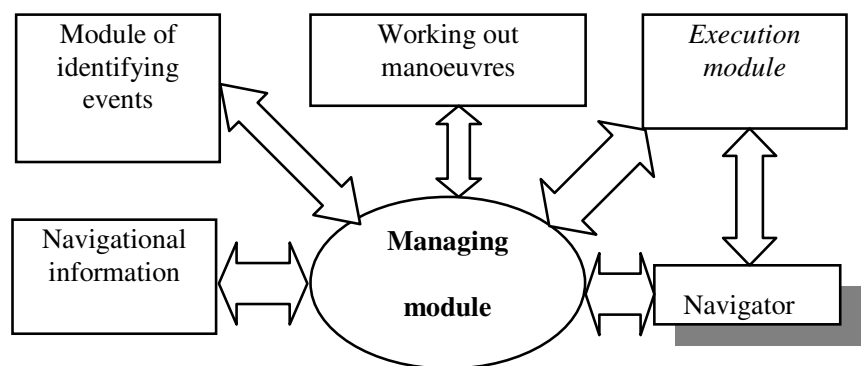

Fig. 4. Multi-agent system structure [6]

The system's functioning is based on an algorithm consisting of eleven procedures:

- determining risk of collision (PROCEDURE 1),

- determining phase of encounter (PROCEDURE 2),

- determining right-of-way in relation to extraneous vessels (PROCEDURE 3),

- calculating changes of course and speed leading to mutual passing on a preset CPA (Closest Point of Approach) (PROCEDURE 4),

- $\quad$ working out a manoeuvre (PROCEDURE 5),

- last-moment manoeuvre (PROCEDURE 6),

- admissible intervals of course and speed alterations (PROCEDURE 7),

- decreasing the assumed CPA (PROCEDURE 8),

- manoeuvre in relation to vessel with smallest TCPA (Time to Closest Point of Approach) (PROCEDURE 9),

- optimisation of manoeuvre (PROCEDURE 10),

- $\quad$ performing the manoeuvre (PROCEDURE 11).

Basic criteria for the assessment of the navigational distance are Closest Point of Approach (CPA) and Time to
Closest Point of Approach (TCPA). They are commonly used in Automatic Radar Plotting Aids (ARPA).

$$
\begin{gathered}
C P A=\frac{X_{w z} V Y_{w z}-Y_{w z} V X_{w z}}{V_{w}} \\
T C P A=\frac{X_{w z} V Y_{w z}-Y_{w z} V X_{w z}}{V_{w}^{2}}
\end{gathered}
$$

where:

$V X_{w z}, V Y_{w z}$ - relative speed vector components,

$X_{w z}, Y_{w z} \quad-$ distance between vessels counted along $\mathrm{x}$ and $\mathrm{y}$ axes, respectively,

$V_{w} \quad-$ relative speed.

Determination of the ship's own course for the passing of an object at a given distance is possible depending on the analytical [11]:

$$
\begin{aligned}
& \operatorname{tg} \frac{\psi}{2}=\frac{A_{C P A} V \pm \sqrt{\left(A_{C P A}^{2}+1\right) V^{2}-B_{C P A}}}{B_{C P A}-V} \\
& A_{D C P A}=\frac{X_{w z} Y_{w z} \pm C P A \sqrt{D^{2}-C P A^{2}}}{X_{w z}-C P A^{2}} \\
& B_{D C P A}=A_{C P A} V_{x}-V_{y}
\end{aligned}
$$

where:

$$
\begin{aligned}
& \mathrm{V} \quad \text { - own ship speed, } \\
& \text { Xwz, Ywz - distance between vessels counted } \\
& \text { along x and y axes respectively, } \\
& V_{x}, V_{y}-\text { components of the velocity vector of own } \\
& \text { ship, } \\
& \text { D - distance between vessels, } \\
& \psi \quad-\text { new course which enables to pass other }
\end{aligned}
$$
targets on presumed CPA.

In a similar way it is possible to determine the speed of own ship, which enables to pass other targets on presumed CPA.

Basing on above equations following source code was developed. The courses leading to pass at presumed distance (Safe_Courses procedure). The courses are calculated on the basis of [5] for each pair: the own ship (number 1) and the target ship $i$ (for $i=2$ to $n$, where $n$ is the number of target ship).

Input data:

- $\quad$ position $(x 1, y 1)$, speed $(V 1)$ and course over ground $(K D d 1)$ of the own ship,

- $\quad$ position $(x i, y i)$, speed $(V i)$ and course over ground (KDdi) of target,

- $\quad$ CPA - safe passing distance set up by navigator Output data:

$<$ gamma $_{\mathrm{i}} 1$, gamma $_{\mathrm{i}} 2>,<$ gamma $_{\mathrm{i}} 3$, gamma $_{\mathrm{i}} 4>$ - sectors of safe courses for pair: the own ship and the target ship number $i$. 


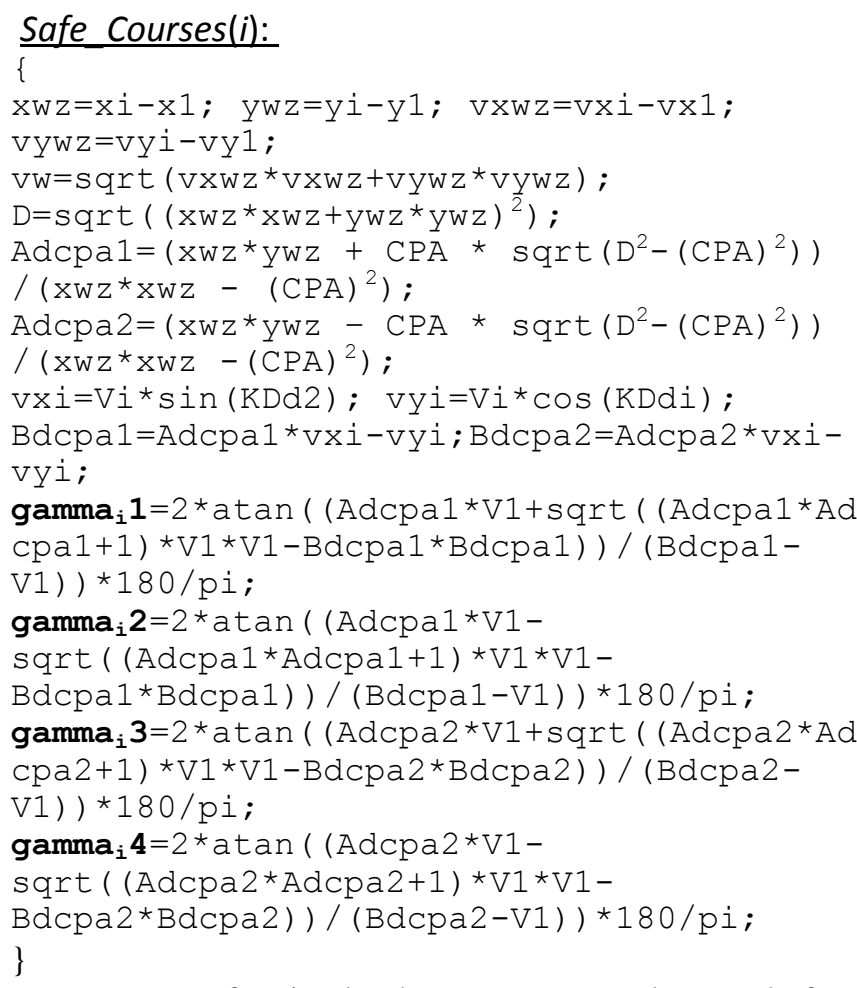

We assume, for simply, that we get as results exactly four angles in the above algorithm for each $i=2$ to $n$. We have to run the above Safe_Courses(i) procedure for each pair: the own ship and the target ship number $i$ (for $i=2$ to $n$ ) and as the result we get all safe sectors $<$ gamma $_{\mathrm{i}} 1$, gamma $_{\mathrm{i}} 2>$, $<$ gamma $_{\mathrm{i}} 3$, gamma $_{\mathrm{i}} 4>$.

Next, we execute the Common_Safe_Sectors procedure for all target ships as the angle intersections of all safe sectors $<$ gamma $_{\mathrm{i}} 1$, gamma $_{\mathrm{i}} 2>,<$ gamma $_{\mathrm{i}} 3$, gamma $_{\mathrm{i}} 4>$ (for $i=2$ to $n$ ). The details of step one can be found in [12]. Let's denoted by gamma ${ }_{j}$ elements of common safe sectors.

\section{V.VERIFYING}

Testing of NAVDEC on $\mathrm{m} / \mathrm{f}$ Wolin was carried out on open sea in the period of four months.

There were following aims to verify during testing period:

1. Correctness of encounter parameters - to be verified by ARPA and Full mission simulator.

2. Correctness of new courses (which lead to pass other targets on presumed CPA) calculation - to be verified by radar and Full mission simulator.

3. Reaction of the system for changing initial settings - to be verified by Trial manoeuvre.

Next few figures present screenshots from NAVDEC interface.

During four months $\mathrm{m} / \mathrm{f}$ Wolin made almost hundred voyages from Świnoujście to Tralleborg. During each voyage there were tens of collision situation (actual CPA were smaller than safe, presumed CPA). One of this is presented on figure 5 .

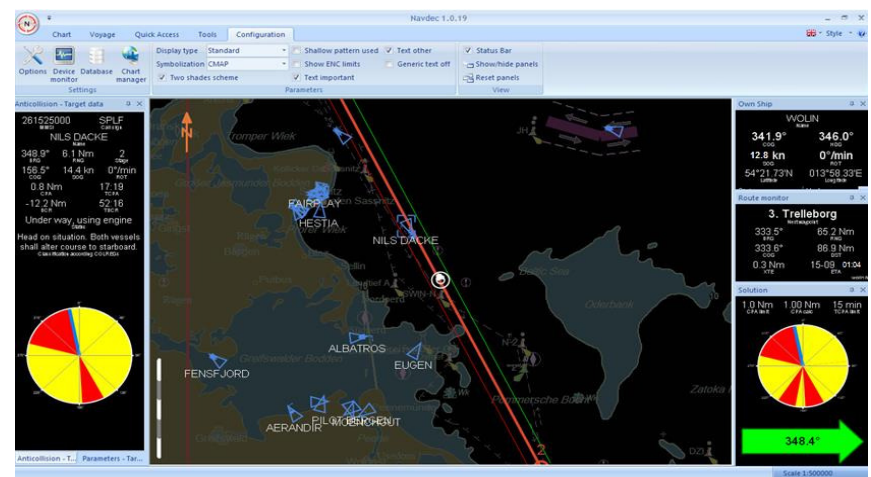

Fig.5. Encounter situation with $\mathrm{m} / \mathrm{f}$ Nils Dacke.

In the situation presented on figure 5, CPA for target Nils Dacke is $0.8 \mathrm{Nm}$ (Nautical mile). NAVDEC qualified encounter situation as "head on situation". According to Rule 14 of COLREGs, both vessels have to alter course to starboard to avoid collision.

Basing on safe, presumed by navigator CPA, system worked out and presented in the form of rosette sectors of safe courses (yellow) and sectors of dangerous courses (red). If own vessel take course from red sector and other target will keep her parameters, it will not be possible to pass on safe distance, and in critical situation collision vessels can collide. If own vessel take course from yellow sector, vessels will pass each other at least on presumed, safe distance.

The rosette shown in the left hand, down corner is an individual rosette for target, which was selected (by clicking on the chart) by navigator. The rosette presented in the right hand, down corner shows solutions for all targets within determined by navigator distance from own vessel (during tests in was $8 \mathrm{Nm}$ ). It's different that individual one, because two other targets are taken into account in calculation process. Present course of $\mathrm{m} / \mathrm{f}$ WOLIN $\left(341.9^{0}\right)$ is within red sector, this is why system NAVDEC displayed also suggested, optimal course. It's presented in the right hand, down corner in the form of green arrow with printed course $\left(348.4^{0}\right)$, which enables both vessels to pass on presumed 1 $\mathrm{Nm}$, which is in accordance of COLREGs and requires smallest deviation from presents course. Additionally, color of the arrow suggests to navigator direction of deviation i.e. green means "to starboard".

The figure 6 presents system "behavior" in dense traffic situation. During each voyage, $\mathrm{m} / \mathrm{f}$ Wolin crosses twice Traffic Separation Scheme (TSS).

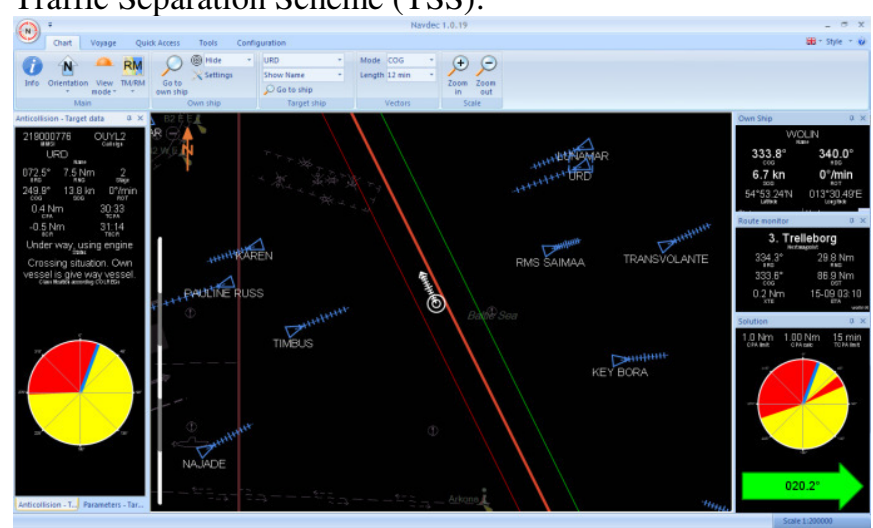

Fig.6. Dense traffic situation. 
In this situation, CPA in relations to „Urd" (report displayed) and „Lunamar” is smaller than presumed $1 \mathrm{Nm}$. Additionally others targets should be taken into consideration when planning anti collision manoeuvre.

Individual rosette of target „Urd”, dangerous sector is arround $110^{\circ}$ (from arround $270^{\circ}$ to $20^{\circ}$ ). On the common rosette, that sector is gradually increased both from left side (target „Lunamar”) or starboard side (targets „Timbus” and „RMS Saimaa”). According to the COLREGs, own vessel is give way vessel in relation to targets „Urd” and „Lunamar”. System NAVDEC has qualified encounter situation as „crossing situation” (Rule 15 of COLREGs) and suggested to alter course to starboard on course $020.2^{0}$ (green arrow). Such manoeuvre enables to pass with all targets within 8 $\mathrm{Nm}$, on the safe, presumed distance of $1 \mathrm{Nm}$.

\section{RESULTS}

Testing of NAVDEC on $\mathrm{m} / \mathrm{f}$ Wolin was carried out on open sea from December 2014 to April 2015. Results, in general, are positive. In details system correctly calculates encounter parameters like CPA and TCPA. Displayed parameters were each time compared with ARPA. Additionally CPA and TCPA calculated by NAVDEC were compared with encounter parameters calculated by Full mission bridge simulator. Results show that NAVDEC is more precisely than ARPA particularly when ships are manoeuvring. In the first phase of manoeuvre CPA and TCPA presented by ARPA are useless and should not be taken into account in evaluation of encounter situation as it could lead of its misjudgment. Moreover NAVDEC informs navigator that targets have started their manoeuvres. In such situation target ship is flashing yellow. This function is not available in ARPA. Moreover:

1. In all verified cases own and target data, as well as encounter parameters presented by NAVDEC were correct,

2. In all verified cases qualification of encounter situation done by NAVDEC were according COLREGs,

3. In all verified cases NAVDEC correctly calculates and presents suggested, optimal anti collision manoeuvre,

4. In all verified cases NAVDEC correctly calculates and presents sectors of safe anti collision manoeuvres.

\section{IMPLEMENTATION}

NAVDEC will find application on vessels and in land-based centres as an independent system or a module added to the existing navigational systems. Its main areas of use include:

- navigation-related decision support in collision situations - shipboard decision support system installed on the navigational bridge of merchant vessels (sea-going and inland shipping) and leisure boats (e.g. sailing ships, motor yachts)
- navigational decision support in collision situations component of land-based vessel traffic services systems (VTS, VTMS, VTMIS, RIS)

- analysis and assessment of marine accidents at sea and on inland waterways - a system intended for experts working for maritime courts

- marine officer training centres offering courses in the Collision Regulations - a module of navigational simulators (e.g. ship-handling, ECDIS)

At present, the system is developed for operation in the open sea, so emphasis is put on developing functionalities for navigation in restricted waters. This is related to issues such as navigational restrictions of a water area and requires applications of advanced methods and tools of dynamic optimization.

It is also planned to develop versions of the system for marine training centres for ship-handling simulators and in longer term system functionalities for VTS centres will be extended with functionalities aiding vessel traffic control and management.

An example of analysis of marine accidents is presented below.

Based on the data included in the report [13], a simulation was made to determine parameters of the encounter and to generate possible anti-collision manoeuvres at certain moments of time. The solution does not account for manoeuvring components (kinematic equations). Figure 7 presents a reconstructed situation at $0900 \mathrm{hrs}$. The range of courses that assure safe passing at the preset CPA or larger is marked yellow on the circle. The recommended manoeuvre is indicated as 'NEW COURSE' and enables the ships to pass each other at the assumed CPA. The speed range satisfying the assumed criteria is marked green, and proceeding at 'NEW SPEED' will result in the ships' distance during passing being equal the assumed CPA. At operator's request, the system can display the recommended trajectory based on the generated solutions and the next waypoint (Figure 8).

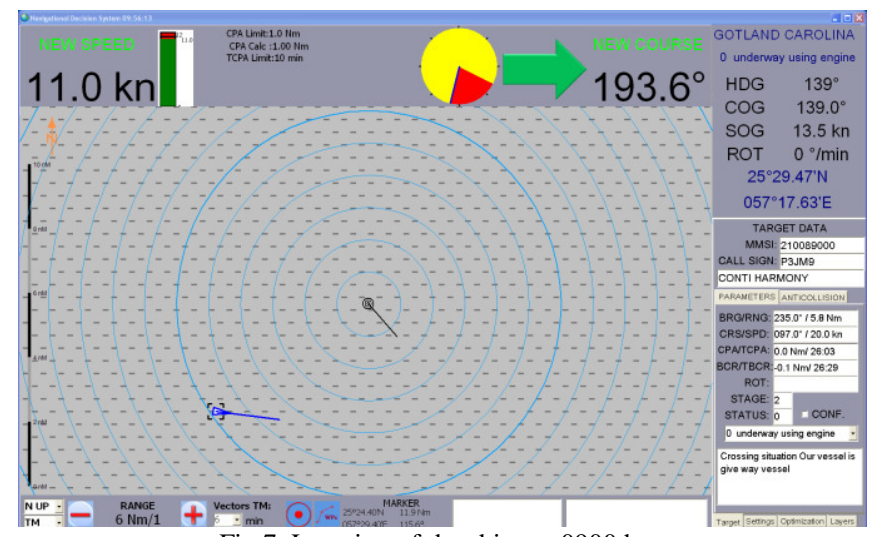

Fig.7. Location of the ships at 0900 hrs. 


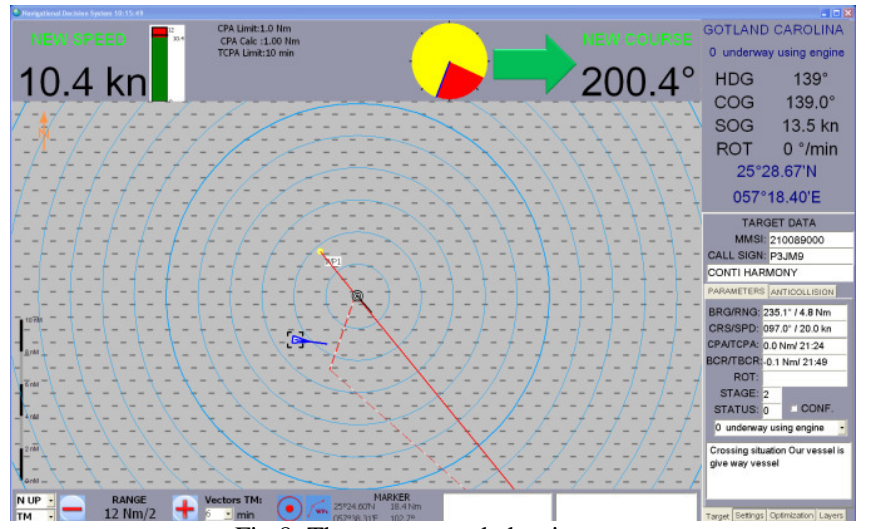

Fig.8. The recommended trajectory.

When the recommended manoeuvre is performed by own (system operator's) ship, the system assesses the situation as safe (green ship contour - Figure 9), as all the criteria have been satisfied. At the same time, in line with COLREGs, the situation remains qualified as before, so our (operator's) ship is still the give-way vessel.

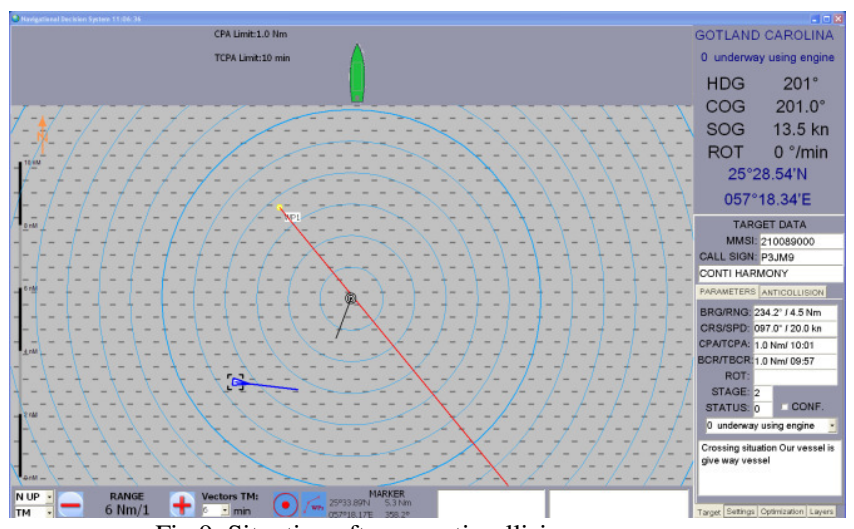

Fig.9. Situation after an anti-collision manoeuvre.

If the navigator does not take a preventive action, the system will continue to work out manoeuvres to be performed. If a collision cannot be avoided by altering course to starboard or by changing speed, proposed course alterations to port will be displayed (Figure 10).

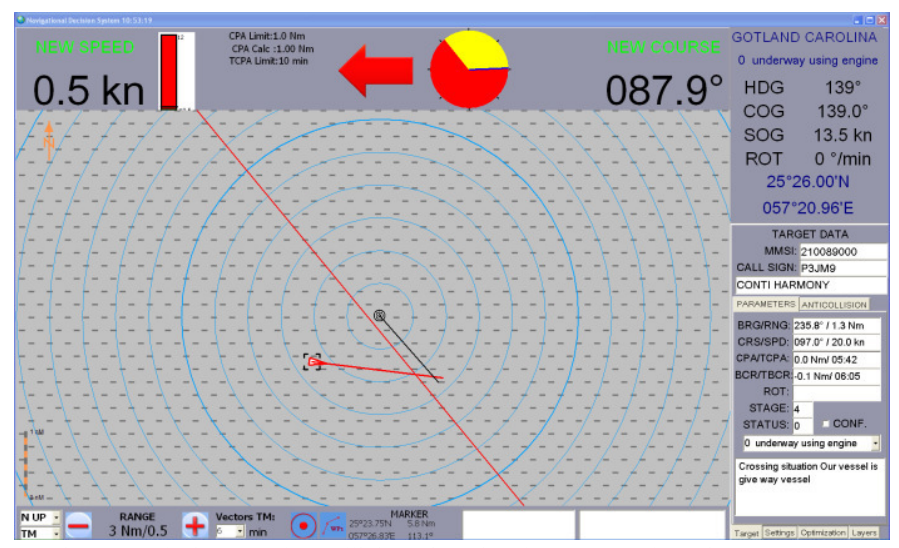

Fig.10. Solutions to the collision situation by course alteration to port.

At the time the ships come to a point where passing at distance of $1 \mathrm{Nm}$ will not be possible, the system automatically reduces the assumed CPA by half. The new CPA taken into account while generating an anti-collision manoeuvre is displayed at the top screen denoted by CPA Calc (Figure 11).

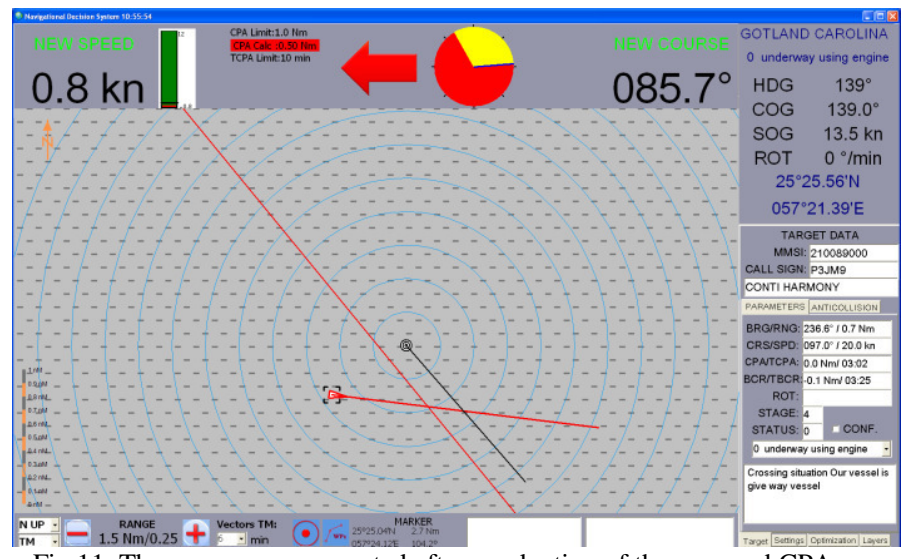

Fig.11. The manoeuvre generated after a reduction of the assumed CPA.

Future trend innovation leverage will be the coupling of NAVDEC with the ship's operational systems and equipment to enable automatic anti-collision manoeuvres. With such extension, the system will become a principal component of unmanned vessel control system. [14]

System is already installed on 13 ships.

\section{VIII.CONCLUSION}

According to the reports from the States in Baltic region there were 149 ship accidents in the HELCOM area in 2012 (Figure 12), which is 6 more than the year before (increase of $4 \%$ ) and 19 more than in 2010 (increase of 15\%).

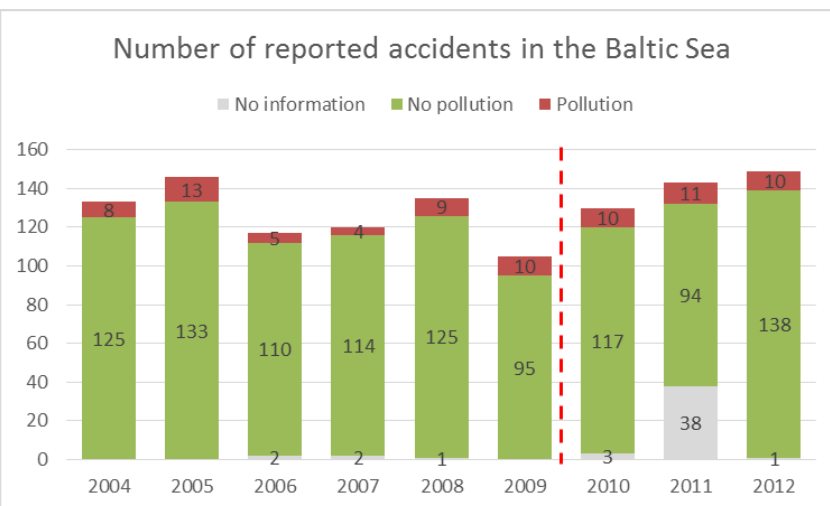

Fig. 12. Accidents in Baltic region in the period 2004-2012[4].

On the figure 13, there are statistical information from insurance company The Swedish Club. 


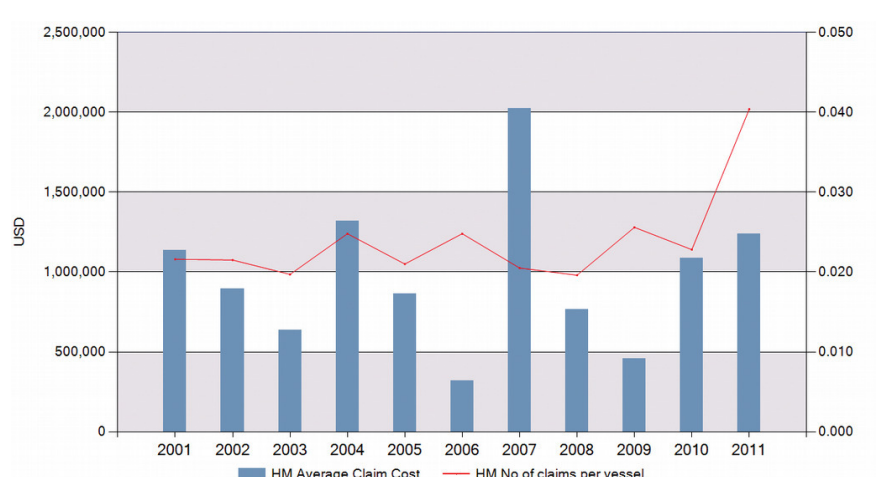

Fig. 13. Average claim cost \& frequency $2001-2011$, limit $>=$ USD 10000 [2]

According data presented above, average cost of collision is more than 1 million USD. The Swedish Club shares $13.6 \%$ (2010) of hull and machinery insurance global market. According Figure 5, around $2.5 \%$ of vessels are in collision every year i.e. over 1,900 . In this situation the total cost of collisions is around 2 billion USD per year. According data from International Union of Marine Insurance, worldwide premium volume in 2013 was 34.2 billion USD. [14]

NAVDEC gradually increases functionality of existing navigational systems [15]. First of all it qualifies encounter situations according COLREG. Navigator receives notification if she is stand-on or give way vessel and from which rule it comes from. Moreover system gives ready solution of collision situation i.e. save courses and speeds which enable to pass with other targets on assumed CPA. Additionally suggested trajectory is presented on the chart [16].

If mandatory installation of a navigational decision support system reduces number of collision only by $1 \%$, total savings, only for insurers, will be around 20,000,000 USD per year. The collision between Gotland Carolina and Conti Harmony is a proof that this percentage will be much higher.

\section{FUTURE WORK}

Author presented the results of verification of decision support system in real condition. The system involves a number of simplifications for the meeting stages, which have a place in the decision making process. In addition, implementation of the algorithm in the NAVDEC system will require taking into account the limitations of restricted area during the manoeuver and moving away from the assumption that ships can only manoeuver by course and not by course and speed. Besides, the key point of the proposed algorithm, selected by the frame will require the use of the heuristic method with the low time complexity. In the first step author will attempt to apply solutions based on ant colony algorithm described in [17], game control [18], genetic algorithms described in [19] and [20] or evolutionary algorithms described in [21] or ant colony z algorithm described in. Exit condition of the loop will also require the use of fast solutions in the field of computational geometry.

\section{REFERENCES}

[1] http://albumpolski.pl/artykul/polskie-statki-cz-2

[2] The Swedish Club, Collisions and Groundings, www.swedishclub.com

[3] Project Horizon 2012 Research Report, www.project-horizon.eu

[4] HELCOM Baltic Marine Environment Protection Commission, Shipping accidents in the Baltic Sea in $2013 \mathrm{http}: / /$ helcom.fi

[5] Sub-Committee On Navigation, Communications and Search and Rescue, e-Navigation Strategy Implementation Plan, January 2015

[6] J. Magaj, P. Wołejsza, Algorithm of working out anticollision manoeuvre by decision-supporting system, Advanced Computer Systems (ACS 2008), Międzyzdroje 2008.

[7] J. Magaj, P. Wołejsza, Analysis of possible avoidance of the collision between $\mathrm{m} / \mathrm{v}$ Gotland Carolina and $\mathrm{m} / \mathrm{v}$ Conti Harmony, Annual of Navigation No 16, pp 165-172, Gdynia 2010.

[8] Z. Pietrzykowski, P. Borkowski, P. Wołejsza, NAVDEC - navigational decision support system on a sea-going vessel, Scientific Journals Maritime University no 30 (102), pp. 102-108, Szczecin 2012.

[9] J. Koszelew, P. Wołejsza, Last minute manoeuvre as a part of maritime transport logistic system, Logistyka, No 4, 2014.

[10] A. Lisaj, The Method of the Navigation Data Fusion in Inland Navigation. Marine Navigation and Safety of Sea Transportation, Navigational Problems, pp.187-193, CRC Press 2013.

[11] A. Lenart, Manoeuvring to required approach parameters - CPA distance and time. Annual of Navigation 1/1999.

[12] P. Wołejsza, Multi-agent decision support system in collision situation, dissertation, Maritime University of Szczecin, 2008.

[13] Danish Maritime Administration, Casualty investigation reports, www.dma.dk

[14] Z. Pietrzykowski, P. Borkowski, P. Wołejsza, Maritime Intelligent Transport Systems, Communication in Computer and Information Sciences, Telematics in the Transport Environment, Springer Verlag Berlin Heidelberg, pp. 284-292, 2012.

[15] P. Wołejsza, Functionality of navigation decision supporting system NAVDEC, Marine Navigation and Safety of Sea Transportation, Navigational Problems, pp. 43-46, CRC Press 2013.

[16] J. Koszelew, P. Wołejsza, Anticollision manoeuvre optimization in the NAVDEC system, 2014, Advanced Computer Systems (ACS 2014) Przegląd Elektrotechniczny No 2/2015 pp. 27-30 http://pe.org.pl/abstract pl.php?nid=9004

[17] Ming-Cheng Tsou, Chao-Kuang Hsueh, The study of ship collision avoidance route planning by ant colony algorithm, Journal of Marine Science and Technology, Vol. 18, No. 5, pp. 746-756 (2010)

[18] J. Lisowski, The sensitivity of computer support game algorithms of a safe ship control. International Journal Applied Mathematics and Computer Science, Vol. 23, No 2, 2013, pp. 10.

[19] J. Koszelew, K. Ostrowski, A genetic algorithm with multiple mutation which solves orienteering problem in large networks, Computational Collective Intelligence - Berlin : Springer-Verlag, 2013, 356-365

[20] R. Szłapczyński, J. Szłapczyńska, On evolutionary computing in multi-ship trajectory planning, ApplIntell (2012) 37:155-174, DOI 10.1007/s10489-011-0319-7

[21] R. Śmierzchalski, Z. Michalewicz, Modelling of a ship trajectory in collision situations at sea by evolutionary algorithm. IEEE Transaction on Evolutionary Computation, Vol. 4, No. 3, 2000, 227-244. 